\title{
Carbon prices are still far too low to prevent climate change
}

Written by: Kurt Van Dender, Centre for Tax Policy and Administration

Last update: 25 June 2018

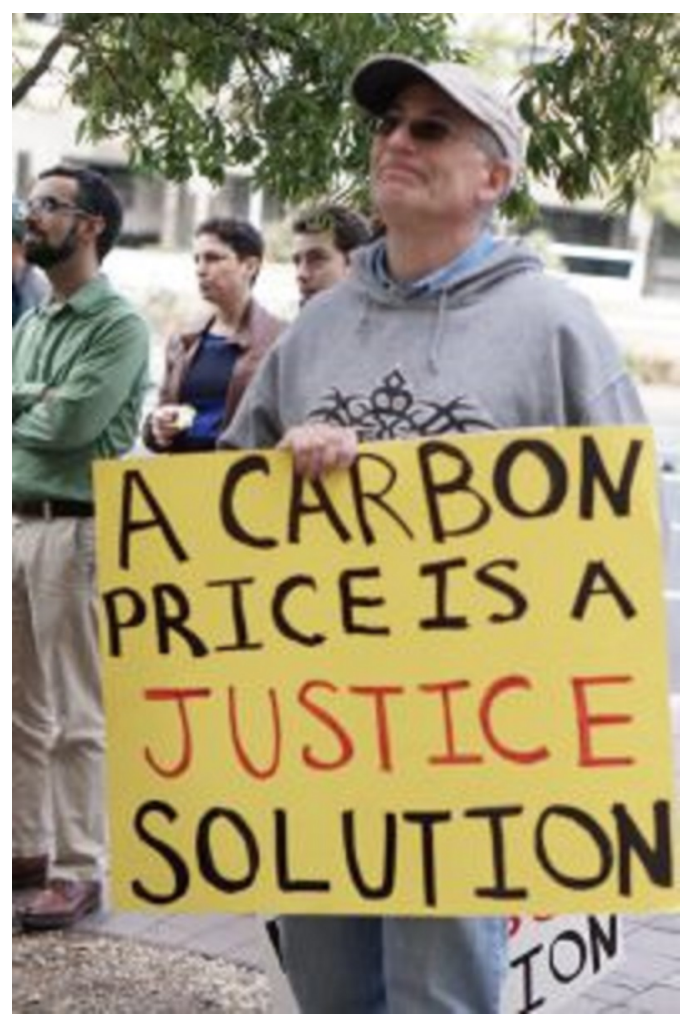

Pricing carbon is one of the surest policy means we know for curbing greenhouse gas emissions and meeting the targets of the Paris Climate Agreement agreed in 2015. Has there been any progress with its implementation since then? Not enough, is the verdict of some of the world's leading experts.

Some $85 \%$ of global emissions are currently not priced, according to a report issued in May 2017 by a High-Level Commission on Carbon Prices, co-chaired by Joseph Stiglitz and Lord Nicholas Stern, both respected figureheads in the fight against climate change. Moreover, about three quarters of the emissions covered by a carbon price are priced below USD 10 per tonne of $\mathrm{CO} 2$ (tCO2). 
That price is much too low, since according to the report, if we are to achieve the Paris temperature target the explicit carbon-price level should be at least USD 40-80/tCO2 by 2020 and USD 50-100/tCO2 by 2030 .

One gap in these numbers is that they do not take into account excise taxes on the likes of transport fuel, heating and energy use more widely, that have virtually the same behavioural impacts as more narrowly defined carbon taxes, and should therefore also lead to reduced emissions.

If these rather commonplace excise taxes on energy use are added into the mix, we can form a broader view of how carbon emissions are currently being priced. To gauge this, we have developed "effective carbon rates", which are made up of all specific taxes on energy use, carbon taxes, and prices of tradable emission permits. This database, which we presented in our 2016 OECD report on Effective Carbon Rates, calculates effective carbon rates for 41 OECD and G20 countries, covering $80 \%$ of global energy use and the associated carbon emissions.

In one sense, the picture that effective carbon rates depict is a little brighter than that presented by Messrs Stiglitz and Stern, as it includes a broader range of taxes, so higher rates. In another and more fundamental sense, the picture actually is a little darker, as effective carbon rates show the enormous size of the challenge we face in battling down greenhouse gas emissions, even when taking a broader view of carbon pricing.

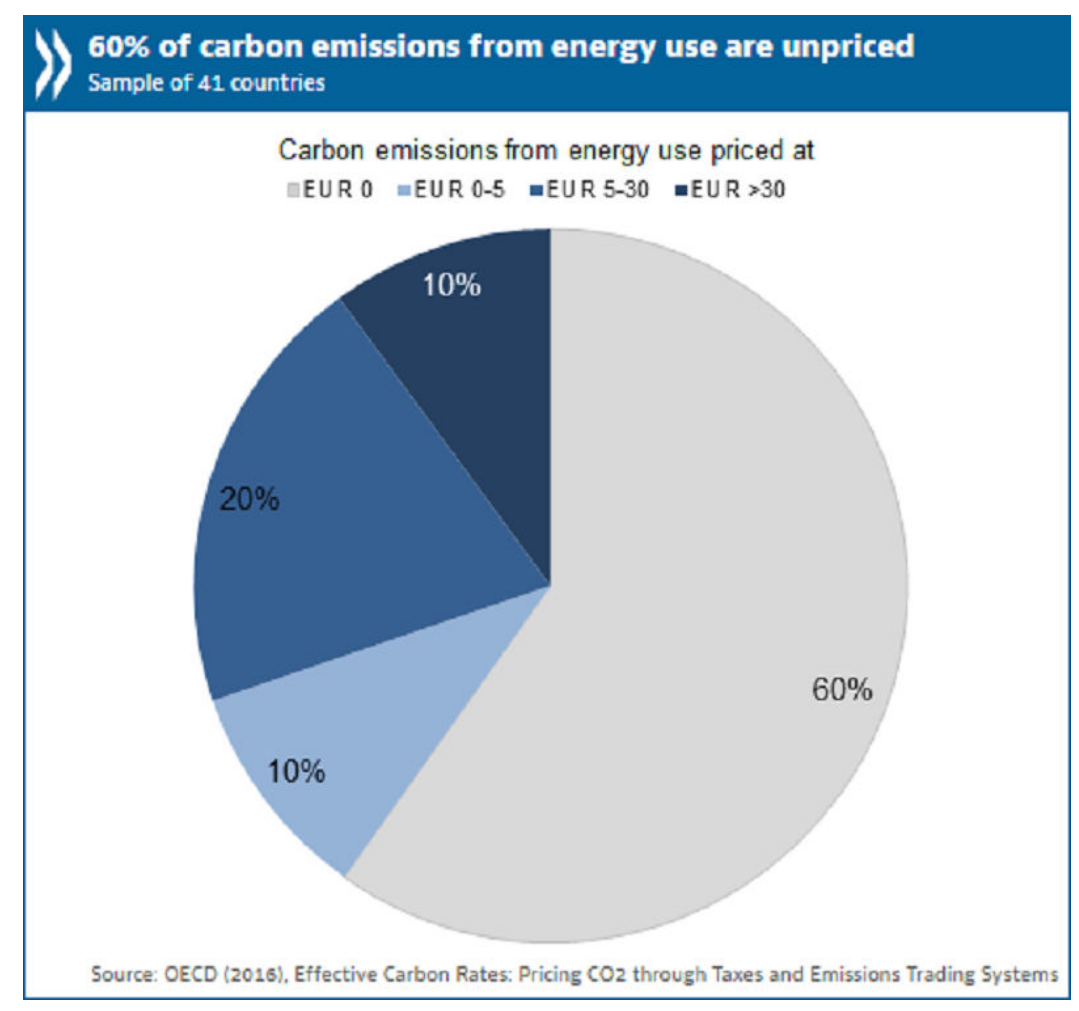

Indeed, according to our database, $60 \%$ of emissions from energy use in the 41 countries are currently not priced (compared with $85 \%$ in the commission's 
report). However, some 78\% of emissions are priced at less that EUR 10/tCO2, which is no less discouraging. So while our more comprehensive estimates indicate that carbon pricing is more widespread than the High Level Commission's report suggests, they nevertheless reinforce the Commission's main point that carbon pricing still only plays a very limited role, and that we are a far cry from what is required to reach the Paris Agreement objectives.

The High Level Commission estimates that carbon prices should range between EUR 40 and EUR 80/tCO2 in 2020 for the Paris Agreement targets to have a chance of being met. Currently, effective carbon rates are below EUR 40/tCO2 for $93 \%$ of emissions, and are below EUR 80/tCO2 for 95\% of emissions. Omitting road transport (where excise taxes are relatively high) from the calculation increases these shares to $99 \%$.

In short, almost no emissions from energy use are priced at levels required to keep global temperature increases below 2 degrees Celsius limit, beyond which climate change could spin out of control. The world's leaders understood the gravity of this prospect by signing up to the Paris Climate Agreement. It is now critical that they take the policy action needed to meet those goals, and that means increasing carbon prices now.

almost no emissions from
energy use are priced at
levels required to keep
global temperature
increases below 2 degrees
Celsius limit, beyond which
climate change could spin
out of control

\section{Related even $\mathbf{t}$}

COP23 side event: Carbon pricing for the low-carbon transition, 15 November 2017, Bonn, Germany: http://www.oecd.org/tax/tax-and-

environment.htm\#COP23-tax-env-event.

More about the OECD at COP23: http://www.oecd.org/environment/cc/cop23.htm.

\section{References}

High-Level Commission on Carbon Prices (2017), Report of the High-Level Commission on Carbon Prices, World Bank, Washington, DC. License: Creative Commons Attribution CC BY 3.0 IGO, https://static1.squarespace.com/static/ 54ff9c5ce4b0a53decccfb4c/t/59b7f2409f8dce5316811916/1505227332748/ CarbonPricing_FullReport.pdf

Visit: https://www.carbonpricingleadership.org/report-of-the-highlevelcommission-on-carbon-prices

OECD (2016), Effective Carbon Rates: Pricing CO2 through Taxes and Emissions Trading Systems, OECD Publishing, Paris, https://www.oecd-ilibrary.org/ taxation/effective-carbon-rates_9789264260115-en

Investing in Climate, Investing in Growth http://dx.doi.org/ $\underline{10.1787 / 9789264273528-e n}$ 